To cite this paper, please refer to the published version:

del Rio Carral, M., \& Lyons, A. (in press). Embodying health behaviours in everyday life: The social and gendered practices of senior female managers, Psychology \& Health. pp. 1-19. doi: 10.1080/08870446.2020.1743292 


\title{
Embodying health behaviours in everyday life: The social and gendered practices of female senior managers
}

\author{
María del Río Carral1, Antonia Lyons2 \\ 1 Institut de Psychologie, Université de Lausanne, Suisse \\ 2 School of Health, Victoria University of Wellington, New Zealand
}

\section{Corresponding author:}

María del Río Carral

Institut de Psychologie, Université de Lausanne

Mouline-Géopolis, 1015 Lausanne

Switzerland

e-mail: maria.delriocarral@unil.ch

\begin{abstract}
Objective: This article extends current theorising around health behaviours using insights from a study with women working in senior management positions in Switzerland. The study aimed to explore the meanings they attached to their everyday activities and examine implications for health and wellbeing by drawing on 1) social practices theory, 2) a socioconstructionist approach to gender, and 3) conceptualisations of embodiment.

Design: Twenty female senior managers were interviewed at two time points 6 months apart: the first interview elicited highly-detailed, descriptive accounts of activities during the previous day, while in the second interview participants reflected on their previous accounts and discussed the meanings they ascribed to their activities. A thematic and narrative analysis of both sets of transcripts was conducted.

Results: Three main themes captured the ways female senior managers talked about their everyday behaviours, all focused around their bodies: 'Functional bodies: Being on-the-go and meeting responsibilities'; 'Limiting bodies: Threats to everyday activities'; and 'Intentional bodies: Activities for wellbeing'.
\end{abstract}


Conclusions: Results are considered in terms of contemporary postfeminist/neoliberal discourses in Western societies, how these are shaping and affecting everyday practices and subjectivities, and their consequences for women's health and wellbeing at work.

Keywords: embodiment, health behaviours, professional identity, postfeminism, neoliberalism, social practices

\title{
Embodying health behaviours in everyday life:
}

\section{The social and gendered practices of female senior managers}

\begin{abstract}
Objective: This article extends current theorising around health behaviours using insights from a study with women working in senior management positions in Switzerland. The study aimed to explore the meanings they attached to their everyday activities and examine implications for health and wellbeing by drawing on 1) social practices theory, 2) a socioconstructionist approach to gender, and 3) conceptualisations of embodiment. Design: Twenty senior female managers were interviewed at two time points six months apart: the first interview elicited highly-detailed, descriptive accounts of activities during the previous day, while in the second interview participants reflected on their previous accounts and discussed the meanings they ascribed to their activities. A thematic and narrative analysis of both sets of transcripts was conducted.

Results: Three main themes captured the ways female managers talked about their everyday behaviours, all focused around their bodies: 'Functional bodies: Being on-the-go and meeting responsibilities'; 'Limiting bodies: Threats to everyday activities'; and 'Intentional bodies: Activities for wellbeing'.

Conclusions: Results are considered in terms of contemporary postfeminist/neoliberal discourses in Western societies, how these are shaping and affecting everyday practices and subjectivities, and their consequences for women's health and wellbeing at work.
\end{abstract}


Much research demonstrates that wellbeing at work is linked to health and illness outcomes (MacDonald, 2005). Health behaviours are often key mediating factors in these relationships. Workers who are stressed or feeling unsupported engage in more unhealthy behaviours than other workers, such as drinking more alcohol, eating a poorer diet, getting less sleep (or sleep of poorer quality), engaging in less exercise, and smoking more (Nelson \& Burke, 2018; Ogden, 2012). Attempts to manage worker wellbeing, to ensure healthy workforces and fulfilment of work obligations, have primarily focused on educating staff about the importance of looking after oneself, and taking responsibility for engaging in healthy behaviours (Tomkins \& Pritchard, 2019). Such 'healthism' is apparent more broadly, where responsibility for health and wellbeing are placed on the individual (Crawford, 1980; Crawford, Lingel, \& Karppi, 2015). These are in line with neoliberal forms of governance that emphasise individual responsibility, agency, choice and self-regulating subjects (Gill, Kelan $\&$ Scharff, 2017). In this paper, we draw on ideas from social practices theory (SPT), conceptualisations of gender and embodiment to theorise behaviours related to work and health among senior female managers. Nowadays positioned as the epitome of professional success, these women are most likely to evolve in highly competitive industries (e.g. finance, law) where senior positions remain primarily dominated by men (Acker, 2006; Chowdhury \& Gibson, 2019; McRobbie, 2007). Moreover, the neoliberal ideals of contemporary culture tend to play out in such workplaces (Gill, 2017). This paper aims to explore the contextualised, gendered, and embodied nature of women's practices in this context, and to analyse the implications of meanings they attach to these practices for their overall health and wellbeing.

Health psychology and related disciplines have a long scientific tradition of studying the role of individual behaviours in health and wellbeing (e.g. Engel, 1977; Matarazzo, 1980; Ogden, 2012). Many health behaviour models aimed to predict - and intervene in - individual behaviours by focusing on intentions, attitudes, and beliefs (e.g. Health Belief Model (Godin \& Kok, 1996); Theory of Planned Behaviour (Ajzen, 1985). These models view health-related behaviours as discrete entities that can be identified and isolated from their context, and that can generate generalized knowledge able to be applied reasonably universally (Chamberlain $\&$ Lyons, in press). The effectiveness of such models has been relatively limited (Ogden, 2003; Mielewczyk \& Willig, 2007; Sniehotta, Presseau, \& Araujo-Soares, 2014) yet they remain popular, perhaps because they reproduce values that fit with contemporary Western societies (Gergen, 2015). These values privilege the rhetoric of individual choice, freedom, 
and responsibility (Beck \& Beck-Gernsheim, 2002; Elias \& Gilles, 2018), and overlook the links between behavioural patterns with broader social structures such as social relations, social infrastructures and materiality, institutions and organisations (Reckwitz, 2002a; Shove, Pantzar \& Watson, 2012). With few exceptions (e.g. Cornish, 2004; Mielewczyk \& Willig, 2007; Laurier, McKie, \& Goodwin, 2000), the complexity of everyday activity, the ways in which people and their bodies engage in everyday activity, and how this affects health remain relatively underexplored (Meier, Warde, \& Holmes, 2018). Below, we theorise health behaviours as everyday activities that are socially embedded, gendered, and carried out through material bodies.

\section{Everyday practices are social}

Social practices theory has been used to theorise the fundamental contextual and social nature of everyday activities. It shifts the focus from individual motivations to the study of activities in the spaces and places in which they take place. Recent studies in public health have analysed social practices as enacted, embodied and negotiated activities in everyday life (Blue, Shove, Carmona, \& Kelly, 2016; Reckwitz, 2002b). They are defined by what people do and how they do it, as well as by how others perceive their actions (Kelly \& Barker, 2016). They are activities that are given meaning through cultural and discursive realms but are also dynamic, non-premeditated, non-reflexive, and not completely rational (Giddens, 1984). Thus, in everyday life, people 'carry' (as well as carry out) social practices that partially preexist beyond 'the individual' (Reckwitz, 2002b). Cultural repertoires are socially available among a given group that induce normalised ways of performing particular activities in specific contexts (Hargreaves, 2011). Social practices can become routines and habits that 'work' under particular conditions when they are sustained through shared patterns of activity. Thus, they are often taken-for-granted and implicit (Berger \& Luckmann, 1991). Simultaneously, social practices are continuously re-constructed and re-created in social interactions through embodied performance (Blue et al., 2016). They also take place and evolve across heterogeneous life domains (e.g. workplace, home, etc.) involving often conflicting meanings and relationships (del Rio Carral, 2015; Hargreaves, 2011). Social practices can be based on tacit knowledge that is not necessarily conscious; feelings are intertwined with meanings and interpretations that affect why, where and how people act, as well as who they act with (Kelly \& Barker, 2016). 


\section{Everyday practices are gendered}

Social practices related to health depend on materials (economic resources, things, places, etc.), competencies (knowing where and when to act in a certain manner), and meanings (socially and culturally constructed) (Reckwitz, 2002a). However, none of these are evenly distributed across society (Blue et al., 2016). Gender is a powerful cultural system for differentiation among groups, set up as a binary division between men and women (Gherardi, 1994). Gender can be apprehended as a situated social practice, like other cultural systems (West \& Zimmerman, 1987). It may be defined as a fluid, twofold process where social structures and individualities are interwoven through practices (Poggio, 2006). This dialectic is composed of 'gendering practices' and 'practising gender' (Martin, 2006). 'Gendering practices' are prescribed by institutions through repertoires of activities that are physically, discursively, and culturally available to be practised in specific social contexts (Martin, 2003). Like other cultural systems, meanings regarding gender shed light upon when and where specific values and norms can be performed, and on what is expected from women or men in particular situations (Gherardi \& Murgia, 2014). The meanings attached to femininities and masculinities varies greatly culturally and historically (Gherardi, 1995). 'Gendering practices' make repertoires available, defining what can be done (or not) within a given organisation (Martin, 2006), such as the way women and men are expected to dress at work, behave in a given social situation, or have particular interests. For example, female managers are expected to be more skilful in mentoring, support or communication compared to their male counterparts (Atwater, Brett, Waldman, DiMare, \& Hayden, 2004). Outside the work domain, care of the body, care of other people's health, and health in general have all been traditionally linked to the feminine realm (Lyons, 2009; Saltonsall, 1993). Inversely, 'practising gender' constitutes the dynamic side of gender, co-constructed through social interactions in specific situations where people may interpret the same practices differently (Poggio, 2006). Meanings of practices can therefore evolve continuously (Gherardi, 1995).

\section{Everyday practices are embodied}

Many scholars have argued that activity is embodied (Blue et al., 2016; Martin, 2006; Riley, Evans, \& Robson, 2018; Thévenot, 2001), whether people are aware of it or not (Nettleton, 2001; Sheets-Johnstone, 2015): we cannot escape our own body (Foucault, 2009). What people feel within their bodies is central to the ways they think about themselves and the world (Merleau-Ponty, 1989). In health psychology, research on the body has been 
influenced by its roots in behavioural medicine and natural sciences (Radley, 1998). The body has been primarily conceptualised from a third person perspective, as an object that is impacted on (e.g. by symptoms, illness). Conceptualising the body as a 'subject', from a firstperson perspective, has received increased attention in recent years, contributing particularly to an in-depth understanding of embodiment in chronic illness (Engman, 2019; Johnson \& Fledderjohann, 2012; Radley, 2000). Yet the body-as-subject is often taken-for-granted, and somehow 'silent' in health behaviour research (Canguilhem, 2002). Some scholars have highlighted that meanings attached to bodily feelings and sensations that give rise to corporeality are actually culturally and historically situated (Cromby, 2007, 2011; SantiagoDelefosse, 2014). Gilleard and Higgs (2015) defined embodiment as capturing the intertwined relationship between corporeality and the social.

These frameworks allow us to think about health and behaviour in more contextualised ways. Everyday practices engage bodies in particular ways for women and men, and in ways that are historically and socially dependent. Cultural values rooted in our contemporary neoliberal societies such as autonomy, individuality, choice, responsibility and freedom (Gill, 2017) influence discourses that normalise definitions of what it is to be a 'good person' often dependent on personal 'choices' around engaging in 'healthy' behaviours. Being responsible for one's health and wellbeing and acting appropriately contributes to being positioned as 'good' citizens (Riley et al., 2018), where those who are not viewed as being responsible may feel excluded or having 'failed'. This has been shown to be especially challenging for women; contemporary discourses about health and wellbeing have a greater impact on women than men (Elias \& Gill, 2018).

Recent research has highlighted the ways in which women's experiences at work are made sense of within a postfeminist discourse (Chowdhury \& Gibson, 2019; Chowdury, Gibson \& Wetherell, 2019). Characterised as a 'sensibility', postfeminism consists of a recent dominant cultural tendency to emphasise how women's bodies, affectivities, and psychic lives have become objects of constant labour, self-discipline, and self-surveillance within neoliberal societies that value individualism, empowerment and choice (Gill, 2017; Winch, 2015). Research highlights that the culturally dominant 'top girl' work identity that is tied to a postfeminist sensibility has some harmful consequences for young professional women (Chowdhury \& Gibson, 2019; McRobbie, 2007). However, researchers have not yet explored more senior working women's embodied, everyday activities and social practices across work 
and other life contexts. The aim of the current study was to explore the everyday, embodied activities of female senior managers across multiple life domains, and investigate implications for their health and wellbeing.

\section{Methodology}

This research was underpinned by a social constructionist perspective (Burr, 2015) in which language is viewed as a major cultural system enabling symbolisation through the (re)production of meanings. Meanings are socially, culturally and historically constructed; they are transformed by people through activity in everyday life (Vygotsky, 1997) and allow us to consider people's own perspectives. The data employed in the current study are derived from a larger longitudinal, qualitative research project investigating well-being in the everyday lives of senior female managers in Switzerland (del Rio Carral, 2014).

\section{Recruitment \& Participants}

Snowballing methods were employed to identify women in Switzerland holding senior management positions. Inclusion criteria included women working full-time or the equivalent of four days a week across a variety of organisations and fields of work. Women from a range of family and living arrangements were encouraged to take part. Potential participants were provided with detailed information about the study and any questions were answered prior to their acceptance to take part. Twenty women holding senior manager positions took part in the study. Participants were European $(n=19)$ and North American $(n=2)$, and they had an average age of 43 years (range from 35-46). All participants worked as company or department head in organisations based in the French-speaking part of Switzerland.

\section{Data collection}

We viewed daily activity as having two key dimensions for the research design: a) an explicit dimension involving actual performed practices within a single day; and b) an implicit dimension involving meanings attached to such practices. Therefore, the study had two stages (Interview 1 and Interview 2) of data collection using specific types of interviews. All interviews were conducted by the first author, a female health psychology researcher younger than the interviewees. In Interview 1, each participant engaged in an individual, structured, face-to-face interview that was designed to elicit descriptive accounts of the woman's actual practices across the entirety of the previous day. The interviewer asked participants to describe chronologically and in detailed, concrete ways, everything they did from the moment 
they woke up until the moment they went to sleep. The focus was kept on performed practices rather than their meanings or the reasons for them. Six months later, all participants engaged in a face-to-face in-depth reflective interview with the same interviewer (Interview 2). The descriptions elicited in Interview 1 were used as material for Interview 2, so women could reflect openly upon them. The 6-month time period provided distance and enabled participants to analyse their own activities as 'new' objects of analysis in more depth than would otherwise occur. Most participants commented that this procedure made them reflect on their intentions and life values from taken-for-granted daily habits. Sixteen interviews were conducted in French and 4 in English, based on participant preference.

\section{Data analysis}

The 40 interviews (20 from Interview 1 and 20 from Interview 2) were fully transcribed by the interviewer. Identifying features (e.g. cities, locations) were changed to ensure anonymity. All participants were given pseudonyms. Transcripts were analysed using both inductive discursive thematic analysis (Braun, Clarke, Hayfield, \& Terry, 2019) - to identify key themes and discourses - and narrative analysis (Murray, 2013) - to capture the storied nature of their accounts. The women reflected on themselves and their lives using a 'story form' in the interviews (Murray, 2003), which involved: a) a certain temporality (within a day in the life punctuated by a specific beginning - waking up - and a specific ending - going to bed); b) different life contexts and social ties and, c) protagonists' making sense of themselves and their daily lives across two interrelated interviews (Interview 1-Interview 2). Analysis was conducted in the original language of the interviews, although all quotes have been translated to English for this article (for the original quotes see [Appendix]). Codes, subthemes, and themes were developed (Braun et al., 2019) drawing on the conceptual understandings of embodiment, social practices theory, and health and wellbeing as outlined earlier.

\section{Findings}

As female managers talked about - and reflected on - their daily activities, they emphasised ways they used and felt their bodies in relation to health and wellbeing. Three themes captured the complex dynamics and embodied experiences of activities across different life contexts (e.g. work, family, social contexts), namely functional bodies, limited bodies, and intentional bodies, as described below. Participants had very similar ways of talking about their embodied activities, perhaps indicating a particular cultural sensibility that focused on success, merit, choice, and sacrifice. 
The female managers frequently discussed how active they were, and how important it was to keep up an active pace to fulfil their daily duties and meet their wide-ranging responsibilities in different areas of their lives. They described their bodies as functional, solid and resistant, often involving intense and fast-paced activity. Work activities were described as requiring an embodied way-of-being in the world that involved constantly being 'on-the-move', which was oriented towards achieving efficiency and high levels of performance. But being constantly on-the-move was also described as a way of 'being' that extended outside of work into home and family contexts. In Extract 1, Carla describes being 'hyper busy' as something she loves and as part of her nature, and constructs 'having nothing to do' as 'depressing':

\section{Excerpt 1: Carla (Interview 1)}

Carla: $\quad$ I cannot stand still, that's a bit of my problem. I cannot remain seated to watch the stars, I need to move, but that does not prevent me from chatting with others. I like doing the laundry while doing other stuff. I cannot contemplate the lake [near her place] just like that without doing something else. It's not in my nature actually. It's a family thing I believe, because my mother is like that, always on the move as they say. And my children are used to this, they usually run behind me! But it's true that I love activity, I love being hyper busy. I'd rather be too occupied than having nothing to do, it's depressing otherwise, it's not in my [silence]

Interviewer: In this sense, working is important to you?

Carla: Definitely. Oh, it's fundamental!

Here, Carla constructs her busy-ness as part of who she is, important to her wellbeing, and as an attitude that other people in her life are used to her adopting. The activities she describes are gendered (doing laundry and childcare) as is the multitasking which is less apparent in men's lives (Bianchi, Milkie, Sayer, \& Robinson, 2000; Kan, Sullivan \& Gershuny, 2011). In constructing herself as needing this level of activity, Carla can describe working as a 'fundamental' part of her life.

Everyday health-related practices, such as eating and sleeping, were frequently described by participants in highly utilitarian ways, activities they engaged in to be able to continue to be busy and active (particularly at work). These activities were presented as needs that the 
body requires, and so participants described planning them to fit into their workday routines. In Excerpt 2 below, Anna (who lives in three different countries to meet professional and family responsibilities), described her basic nature as full of energy, and sleep or rest as a purely functional activity:

\section{Excerpt 2: Anna (Interview 1)}

Anna: That is because I am very efficient in the morning and late in the evening. At 8am, I am immediately operational, directly, completely into it. In the evening, when I leave here [work] at 7pm or 7:30 pm I go home, I rest for one hour and then I'm fully on again.

Interviewer: Until you go to bed.

Anna: $\quad$ Because I say to myself 'it's important to sleep'.

Interviewer: So, you are not even tired by that time?

Anna: $\quad$ No! I am like a battery full of power! It's in my nature, my nature is being energetic.

Anna also describes her busy, energetic way-of-being as 'in her nature'. She later discussed how she was able to intentionally induce sleep at specific places and precise times to ensure her wellbeing and avoid 'reaching her physical limits'. Anna constructed sleep as a voluntary activity to provide rest so that she was able to maintain her active way of being:

\section{Excerpt 3: Anna (Interview 2)}

Anna: I can sleep everywhere, of course. This is what allows me to avoid reaching my physical limits, I think, right? Because whenever I don't need to be active, I switch on the sleep mode in a plane, in a car if I'm not driving. This is not a problem. It enables me to recover in order to start again directly afterwards. Back again with energy.

Eating was also described as a functional activity. For example, Bernadette explained that she ate lunch at her desk, and viewed eating lunch as 'completely utilitarian' where the aim is 'to eat and to have energy', yet to ensure that so she does not feel sleepy afterwards.

\section{Excerpt 4: Bernadette (Interview 2)}

Interviewer: Regarding your lunch, you also mentioned it is utilitarian? 
Bernadette: Totally, it is utilitarian to me, purely! I'm a bit extreme in my personality. For instance, typically to me, well I'm exaggerating perhaps [laughs], but lunchtime is to me a perfect illustration of my own personality. Eating lunch is completely utilitarian. This is why I choose to eat a sandwich. The aim is 'to eat', to have energy. Eating in my own definition of utilitarian should have enough nutritional facts (...). It cannot be too heavy because if I eat utilitarian I must not feel sleepy afterwards.

Participants' active and rushing embodied state affected their health-related practices, but also was a generalized state they experienced within their everyday lives. This was so normalised that many described her being 'inactive' as unbearable psychologically. As Carla notes, this way of being is needed given the circumstances that she describes in her life both at work and at home. She is the head of finances in a large multi-national company, married to a surgeon, and mother of two children, and works late at least three times a week. When reflecting on her day, she identifies two important daily life moments with her children: driving to school every morning and preserving at least one evening per week for them. She describes herself as having a 'very positive nature' and a 'carpe diem' philosophy, and associates this to being onthe-go, even when feeling signs of fatigue:

\section{Excerpt 5: Carla (Interview 2)}

Carla: Me, I need the action mode! And then I write, and then I put things together, but first it's an action-oriented mode, either at home or at work. I need action. I think I cannot stand [silence] I cannot remain inactive when I see other people running around me. I do not understand Madame de Sévigné when she said 'it is sweet to do nothing when everything else whirls around oneself'. Me, it's the other way around. I cannot stay inactive where others are working like crazy around me, it's something that I cannot stand neither at home nor at work. So typically, even the day when I'm feeling tired, and that I see my husband or other people running to the kitchen to clean the table, I cannot stay there to watch, sitting down. But my husband can [laughs]!

Carla's description of not being able to rest while other people are doing chores or working is interestingly linked to social prescriptions on traditional forms of femininity and on those that 
define family division of labour across many Western European countries, where women are often expected to be responsible for the running of the household and domestic chores (Hochschild, 1990; Lyonette \& Crompton, 2015). Research demonstrates that women continue to undertake more unpaid work than men in the homes in this context (Lewis, Campbell, \& Huerta, 2008) and that this 'double-shift' of paid and unpaid household labour has a detrimental effect on health (Lee, 1998). However, this 'on-the-go' corporeal mode involved individualised (and internalised) narratives about handling work and life responsibilities, rather than reflections on a society in which cultural injunctions require - and rely upon - women to be highly-achieving and successful (Chowdhury et al., 2019). Some popular authors have called this mode of being 'rushing woman syndrome', and highlighted that it influences women's physiology through stress hormones and other bodily systems (Weaver, 2017). There are strong resonances between the way participants talked about their 'on-the-go' corporeality and cultural expectations around successful women that are gendered, and historically and socially situated.

A key part of the drive for productivity, efficiency, and action involved gendered power relations and patterns that were apparent across the different contexts of women's lives. At work women described instances of working harder than men, suggesting they had to continually prove their worth. For some women, juggling family, home and work responsibilities meant that health-related practices such as eating and sleeping were described as functional to meet their responsibilities. An active and on-the-go embodied state seemed to be a way for women to feeling control of multiple daily responsibilities (and possibly their lives). In constructing the body in this way, participants derived an enhanced feeling of power, both over their body and over particular situations. This may be why participants found it difficult to rest or slow down, and although they saw this mode of being as key to their wellbeing, it was also linked to physical outcomes such as fatigue, dizziness, and sickness, as described in the next theme.

\section{Limiting bodies: Threats to everyday activities}

In contrast to 'functional' bodies, which were solid, healthy entities, the female managers also discussed situations in which they constructed their bodies as limiting. Most of the time, this was linked to their fast-pace of life, and forced some to consider slowing down. Here, not having a functional body, through fatigue or illness, brought the body to the fore and 
disrupted everyday routines. As Anna describes in excerpt 6, it was acute pain that disrupted her 'intensive pace of constant activity':

\section{Excerpt 6: Anna (Interview 2)}

Anna: Like I'd said: 'my only limit is the physical limit.' I am doing fine as long as my body is fine. 5 years ago, I used to lead this same intensive pace of constant activity and I felt this pain that could have been an infection or anything else! It really hurt! I never go to the doctor, I'm never ill. He told me 'Listen, I don't know what you have, it's an emergency. I had a pyelonephritis which is a severe kidney infection and I told him 'ok, treatment!' - always very pragmatic and told him 'I have to go on business trips in Europe and the United States this week and the week after' He looked at me with these eyes and tells me 'Haven't you understood?' I said 'well let's not exaggerate' and he said 'You choose, but in any case, I will put you on leave for at least one week'! [laughs] But besides sharp pain, I am not familiar with any other symptom.

Anna discusses her symptoms in biomedical terms and is quick to point out this is the only serious illness she has experienced. She draws on medical authority (the doctor) - beyond her own will - to present the pain as 'real', which justifies the need for her to stop and rest in order to recover. For many participants, medical advice to slow down is the only thing that allows them to change their activity when they are unwell. Denying health problems, ignoring symptoms, and continuing to work are associated with traditional forms of masculinity (Lyons, 2009). Perhaps in holding high-powered management positions that have been traditionally held by men, these female managers engage in similar negative health-related practices.

Participants also discussed the limitations of their bodies when they were attempting to make sense of physical signs or symptoms which were interrupting their normal routines and activities. Changes in bodily sensations were only noticed when they abruptly appeared in their daily life impeding their ability to fulfil their everyday obligations. Participants made sense of pain experiences by drawing on the situation and context. For example, Jeanne explained that her experience of having migraine headaches was linked to specific work contexts, particularly when she slowed down after an intensive period of stressful work:

\section{Excerpt 7: Jeanne (Interview 2)}

Jeanne: The migraine, well one of its causes is, well there are many reasons, but I've 
noticed that it comes typically after a period of stress, when I release the pressure, whoosh! I get a really strong migraine, something horrible. It bursts on Friday evening, after the week is over. But it's not just me, it's something typical from people suffering from migraines. It's when you release the pressure. Hence, during periods where I have a lot of migraines, I notice that I am under pressure too, and that even the shortest moment when I release, I feel flaff! That is, I have small physical signs which allow me to consciously realise that I am, yes, that I am under pressure, that I am anxious, that I have let myself overwhelm by the stress at work and that I need to calm down there. That is, when I can do something about it, but [silence]

Here, embodied states are constructed as something beyond one's will, and the body as an autonomous entity separate to the self. Jeanne places the responsibility of getting a migraine on herself and her failure to manage stress, to 'let stress interfere with her health'. This demonstrates 'healthism' in action (Crawford, 1980), where the responsibility for one's health lies within the individual for failing to act in 'proper' ways to avoid illness. Jeanne's selfblame is quickly oriented to what this means for her daily social practices, which is to calm down and slow down, although the difficulty of enacting this is indicated with her 'but' at the end of this excerpt. Besides the physical pain, what primarily affects Jeanne is her realization of the consequences that resting could have upon her daily organisation. However, this bodily sign is an indication to her that she is working too hard, and her 'body is speaking', telling her change is required. Only then does she reflect on the importance of slowing down, and potentially adopting a different pace of activity. At this point Jeanne was silent for a long period; this silence may potentially indicate the limits of discourse, where she does not have the words to explain her thoughts and feelings. The implications of her previous statements raise the possibility of slowing down, and Jeanne's silence may also indicate that this in itself was unsayable (or even unthinkable). Following this silence, the researcher asked Jeanne to further elaborate on how she 'listened' to her bodily symptoms, to which she responded that her bodily signs (of pain) were out of her control. This may have contributed to legitimate, value, and justify her 'on-the-go' embodied mode.

Some participants also talked about experiencing extreme tiredness that limited their active mode. In excerpt 8 below, Greta described her embodied state of extreme fatigue and its consequences: 
Excerpt 8 Greta (Interview 2)

Interviewer: How do you know where to set your limits?

Greta: [silence] Well, there are many factors I suppose. Perhaps when tiredness becomes unbearable. When I'm tired I become quite aggressive, I am sure of that! Also, I don't feel like planning any personal projects or activities anymore, for example, let's say, for the weekend. When my husband and I talk about what we want to do over the weekend, I don't feel like seeing friends, nor going out with the kids, nor anything else for that matter. And that's when I see 'Oh, oh! Attention is needed here! Something must be done here. I must do something different this week or in the upcoming days!' and then that can be readjusted.

Interviewer: What kind of things would you implement when something has to be done?

Greta: These times, I have a baby-sitter that can come on Saturday mornings, so I can do sports during that time. That's two hours just for me - it's little things like that.

Greta's description of her tiredness as 'unbearable' underlines how difficult this embodied experience is for her, linking it to becoming aggressive and lacking desire for her normal social activities. To address this, she engages in practices that involve getting away from her family life for a couple of hours to work out by herself. Similarly, Dalia describes 'extreme weariness' that is a sign from her body that she needs to stop, and thus implying she has little control over this.

Excerpt 9: Dalia (Interview 2)

Interviewer: You were saying that the psychological fatigue is different than the physical fatigue. How do you cope with the physical one?

Dalia: $\quad$ In that case, rest! Imagine, I have even said to myself: 'Now, I am taking a day off, I need to rest'. But those are really extreme situations ok? And in that case, yes, I take a rest.

Interviewer: How do you feel at that moment?

Dalia: Weariness. I don't know how to explain it. Suddenly, there is this huge huge weariness and there I say to myself: 'Now, it's important to stop'. I believe that it's like a sign from the body, that comes to me and says: 'Now, you have to stop' [laughs]. It's like when I told my [male] boss 
after the summer, when I told him: 'Actually, it's after having stopped [working] that I realised how tired I was.' So he said: 'But it's because you never stop!' And I replied: 'Well, you know it's not so easy!' But there are physical limitations to it.

Dalia portrays her 'extreme' tiredness as an overwhelming weariness that becomes more acute once the body has stopped. In this way she describes her body as imposing forced rest. Her discussion with her boss about her tiredness is somewhat different, as she is reflecting on being tired over summer and presumably once she was on holiday, a situation that does not affect her work.

Generally, participants were reluctant to acknowledge any physical limitations because the consequences would have significant repercussions for their everyday lives, including having to slow down and needing to reorganize significant aspects of their lives. This may help explain why most participants tended to overlook potentially negative bodily signs or symptoms for as long as possible. They appeared to be more concerned about holding onto their responsibilities as senior managers, as mothers, and as women, at times to the detriment of their health and wellbeing.

\section{Intentional bodies: Activities for wellbeing}

Participants discussed using their bodies in particular ways to achieve mental relaxation, fight tiredness, distance themselves from their daily obligations and gain new perspectives on their lives. Of note here was the importance of context in achieving these outcomes. Participants intentionally engaged in intense and fast-paced activities in spaces, places, and times that were explicitly outside work and family domains, to induce desired fatigued embodied states. Although they described taking part in these activities to become fatigued, they clearly articulated that this fatigue was different to that arising from keeping up with everyday life obligations. Participants constructed this intentional physical fatigue in positive ways, as having positive psychological effects. For example, in excerpt 10 Beatrice distinguishes work and sports fatigue:

\section{Excerpt 10: Beatrice (Interview 1)}

Interviewer: So paradoxically you feel more rested?

Beatrice: Yes, maybe because this physical fatigue that results from sports is a very different fatigue than the emotional one felt after work. It's not the same 
quality of sleep after one or after the other one. With physical fatigue it's possible to sleep without thinking too much [pause, sighs], yes, that's right, that's right.

Beatrice links physical fatigue from exercise and sports as leading to better sleep quality. Others described how engaging in intentionally planned physical, social, and/or artistic activities allowed them the mental and physical space to distance themselves from their daily obligations and responsibilities. Undertaken in particular contexts, such activities were constructed as experiences that were strongly linked to personal wellbeing in terms of providing psychological and emotional release, balance and distance, as Vera describes:

\section{Excerpt 11: Vera (Interview 1)}

Vera: What seems important to me in order to feel balanced is exercise. I realise that more and more with time. I really need sports to indirectly take distance, as an emotional release. It helps me to think of something else. I really need something physical. Physical work too. Because my work is really intellectual, it's thinking and discussing all the time, while sports is where, my body is present.

Vera contrasts her 'intellectual' paid work - where she is not conscious of the presence of her body - with exercise where her body is present. This way of presenting leisure activities in comparison to her work life leads to constructions of wellbeing defined by feelings of balance and emotional release. When asked to reflect on it, Vera describes feeling different types of energy that she expends in work versus leisure contexts:

\section{Excerpt 12: Vera (Interview 2)}

Interviewer: How is physical energy used at work different from that used for sports?

Vera: $\quad$ In my opinion, I don't really spend energy at work. I mean [pause], there is a real demand for energy at work, but then I need to get this energy back outside work. It's not the same energy. First of all, it's all subconscious at work, but it's conscious outside work. When I do sports or other things it's conscious, it's chosen, it's intentional. The second thing is that I don't feel drained outside work. It's a different energy. 
Participants constructed their experience by highlighting different kinds of fatigue, one 'emotional' and diffuse, felt at work, one 'physical' and concrete, felt through physical leisure activities. They also discussed different qualities of 'energy', where that resulting from work is described as 'draining' while that resulting from leisure activities is a positive outlet and resource. This positive embodied experience relates to contemporary ideals of women's bodies and associated discourses that encourage individuals across Western societies - and particularly women - to engage in body labour to achieve 'healthy', 'fit', and 'thin' bodies (Winch, 2015).

The distinction between different kinds of embodied 'fatigue' did not only hold between work and leisure time however. In the excerpt below, Greta discusses two different kinds of physical activities which have different consequences for her: cycling or spinning classes (and similar exercises) versus the effort of pushing the baby stroller:

\section{Excerpt 13: Greta (Interview 2)}

Great: I enjoy doing spinning very much, since it's a tiring exercise. It's important for me to go jogging or to take my bike, to really get tired physically, but not pushing the stroller from one village to another village. That's also tiring, but it's not the same kind of fatigue!

Greta constructs and experiences exercise quite differently in the two contexts she describes. The first she views as providing wellbeing, while the second she describes as tiring in a different way. The distinction appears to be exercising in a context detached from family or institutional obligations and roles. Senior female managers constructed daily practices that engaged the body in conscious ways to induce particular states, feelings or sensations as important for wellbeing. Our analysis also suggests that such wellbeing can only be achieved by engaging in specific activities outside work and family contexts. In their leisure time, all participants pursued a different form of 'work', one oriented towards their bodies, requiring them to stay 'fit' through 'body work', regulating their feelings and themselves instead of professional and domestic duties. The ways in which bodily sensations and feelings were signified in this theme (e.g. as relaxing, agreeable or revitalizing) were constructed as an important part of health and wellbeing. These narratives are consistent with postfeminist discourses that encourage women to engage in efforts to be self-disciplined and continually working on self-improvement, so that they can be 'good' women and citizens (Riley et al., 2018). Our findings underline the constant labour - at work, at home, and during leisure time 
- that women must engage in to fulfil ideals of success that align to a 'top woman' work identity discourse. This is similar to the 'top girl' notion recently coined for younger successful professional women (Chowdhury \& Gibson, 2019; McRobbie, 2007), except here it involves senior managers. This theme demonstrates that the particular sensibility embodied by these women extends from the workplace to other life contexts, and highlights a need for round-the-clock productivity in one form or another.

\section{Discussion}

Drawing on activity-focused interviews with senior female managers, this study highlighted how activities related to health and wellbeing are inseparable from the influence of social contexts, gender and embodiment. Our analyses demonstrated that embodiment, or ways-of-being in the world with and through the body (Gilleard \& Higgs, 2015), were a key feature in women's descriptions of their activities at work and their daily lives more broadly. Feelings and sensations were interpreted in the light of life contexts, social ties, cultural norms and institutional values, highlighting close links between the corporeal and the social when making sense of daily activity (Cromby, 2007; Lyons \& Chamberlain, 2017).

Women described having 'functional' bodies that were necessary to engage in a range of activities, lead a fast-paced life, and meet all of their responsibilities at work, but also at home. This allowed for ensuring efficiency and performance in specific contexts, as work and family duties required constant activity. This form of embodying daily activities fits within a broader societal - and neoliberal - discourse promoting increased efficiency, individualisation, and productivity (Ehrenberg, 2008). Simultaneously, women construed this busy-ness as arising from a personal choice, or as inherently part of their 'being'. Their narratives echo the complexity of the current cultural and media landscape, where postfeminist discourses accentuate agency, empowerment, merit, agency and choice among women (Gill, 2017). In our study, women portrayed themselves as deliberately choosing their busy work and life situations (Gill \& Donaghue, 2013; Lewis \& Simpson, 2017) as fitting their 'nature'. This is then embodied into their daily lives through actual practices (Lewis \& Simpson, 2017; Martin, 2006). Participants implied feeling empowered by their ability to be constantly energetic, active and in control of their bodies. Here, health-related practices such as eating and sleeping were seen as functional to allow women to continue be active. Considering gender as a practice that is socio-historically situated (Poggio, 2006), the 'functional' body theme suggests that women may be driven by the injunction of being 
successful both at work and at home, and that this may become internalised as a personal 'preference' (Hakim, 2010) or attribute. Becoming 'good employees' and 'good mothers' has been defined as a form of postfeminist rhetoric that blends into women's processes of making sense of themselves, their bodies, and their daily lives (Carlson, 2011).

Contemporary postfeminist and neoliberal discourses can have negative impacts on women's health and wellbeing. Participants described having 'limiting' bodies when they experienced pain, illness, tiredness or fatigue. Here the body moved from the background of daily life to the foreground when it threatened the ability to continue with fast-paced everyday activity. Bodily signs and symptoms were ignored for as long as possible, to avoid a loss of control over daily responsibilities. Medical authority provided a legitimate reason for rest, but little else did. Extreme exhaustion was viewed as a sign from an 'objective' body that rest was required, or else illness would result. Meanings that participants attached to bodily signs very much aligned with traditional masculinity, where little attention has been given to the body or taking care of the body (Gough \& Conner, 2006; Whitaker, Gough, Fawkner, \& DeightonSmith, 2019). These findings imply that societal pressures weigh upon working women via values that compel them to respond to aspirations that are historically both masculine (e.g. achievements in male-dominated work organisations) and feminine (e.g. feminised appearance, care and domestic responsibilities) (Lewis \& Simpson, 2017) in order to be 'successful'. They also contribute to recent critical literature that has highlighted the double injunction arising from postfeminist discourses around the 'top girl' identity among young working women, which reinforces cultural ideals of womanhood (Chowdhury \& Gibson, 2019; McRobbie, 2007).

The 'limiting bodies' theme highlighted that women had some difficulty in attaching meanings to signs of illness, fatigue, or pain within contexts associated with fear or anxiety. In these contexts, women were highly apprehensive about the potential consequences of bodily rest for managing their daily activities. This suggests that self-responsibility works as a rhetoric to make sense of embodiment and, to some extent, health and wellbeing. One of the perverse effects of this may be the fear of 'failing' to meet cultural and, therefore, personal expectations for women, which in turn leads to emotional distress (Chowdhury et al., 2019). In contemporary societies, productivity in the workplace is often pursued to the detriment of workers' health and well-being. These findings demonstrate how understandings and interpretations of the body are shaped by social contexts, institutions and constraints (Riegel, 1976). 
The women also discussed 'intentional bodies' when they consciously planned activities where the body was constructed in particular ways and to induce particular states. Here specific meanings were ascribed to activities in specific spaces and times, such as emotional release, balance or taking a break from daily responsibilities. Here, social practices gave rise to possibilities for women to use their bodies in ways that were highly positive and valued as sources of psychological and physical wellbeing. The positive effects of psychological detachment from work, particularly during leisure time, have been highlighted previously in the literature (ex. Demsky, Ellis, \& Fritz, 2014), and physical activity can be a way of reducing job stress (Sonnentag \& Fritz, 2015). However, our findings provide a more constructionist interpretation. Positive feelings and meanings achieved through physical activity are part of what has been termed 'body work' (Riley et al., 2018). This is an extension of the work that senior female managers engaged in both at the workplace and at home. This mode of making sense of their body, health and wellbeing suggested the difficulty for these 'top women' to slow down, possibly in relation to the experienced cultural injunctions within contemporary societies of being a successful woman (Chowdhury \& al., 2019; Chowdhury \& Gibson, 2019). Interestingly, the women constructed their awareness of their feelings and sensations involved in the 'intentional bodies' theme as insightful, and related to new possibilities of thinking about life, self and others, all described as positive for their wellbeing.

This research highlights the potential of conceptualising health behaviour as practices that are contextualised, gendered and embodied. The 'top women' in this study, holding highstatus jobs in typically male-dominated leadership and senior management roles, attached meanings to their activities oriented by a postfeminist discourse stressing choice, merit, responsibility and empowerment, which was individualised and context-free (Gill et al., 2017). As others have recently argued (Riley and al. 2018), neoliberalism, postfeminism, and healthism play a role in women's sense-making around health, illness, everyday activity and, ultimately, subjectivities. For the women in this study, this cultural context played a role in the interpretation of their body in the workplace and, more broadly, in everyday life (Gilleard \& Higgs, 2015). Driven by narratives of (individual) choice, women prioritised ways of being in daily life that were defined by a constant, intensive activity pace and a solid functional body. This was challenged when they felt signs of illness and fatigue and had to make sense of a 'limited' body, a state they dreaded because of the potential consequences of having to rest. Women managed their health and wellbeing through creating spaces outside institutional 
realms where they intentionally engaged their physical bodies in further 'work' to release stress, pressure and control.

The study was limited by the small sample of senior managers from one geographic location, although it was diverse in that it included parents, non-parents, single women and those in long-term relationships, both heterosexual and lesbian. It was also limited in that quotes were translated into English for analysis and some meaning may have been lost through this process. Finally, even though the 6-month intervening period between Interview 1 and Interview 2 worked well to give participants time to be able to reflect fully on their daily activities, the use of a one-on-one interview with a younger female researcher may have led to particular accounts. There may be alternative ways of eliciting more diverse information and additional insight about women's embodied activities (e.g. using photographs, shared group discussions). Nevertheless, the research did demonstrate the potential of using an activity-based qualitative methodology to access both the social and the psychological dimensions involved in daily activities and health constructions.

At a time when wellbeing and health at work tend to be viewed as individual matters drawing attention away from the key role of organisations - it is necessary to develop alternative theoretical contributions that are able to reflect upon the effects this has on individuals and, particularly, women. This is especially important given the rapid reorganisation of the labour market leading to new forms of employment, more precarity, expectations to work at a faster pace, multiple short-term contracts, and constant evaluation (Moisander, Gross, Eraranta, 2018; Vallas, 2015). In making explicit the potentially negative consequences of contemporary cultural discourses on women's health and wellbeing, it is possible to reframe gendered expectations and identify alternatives that open possibilities for the development of new, healthier forms of social practices and subjectivities. 


\section{References}

Acker, J. (1992). From sex roles to gendered institutions. Contemporary sociology, 21(5), 565-569.

Ajzen, I. (1985). From intentions to actions: A theory of planned behavior. In I. Ajzen, \& J. Kuhl (Eds.) Action control: From cognition to behavior. (pp. 11-39). Berlin, Heidelberg: Springer.

Atwater, L. E., Brett, J. F., Waldman, D., DiMare, L., \& Hayden, M. V. (2004). Men's and women's perceptions of the gender typing of management subroles. Sex roles, 50(3-4), 191199.

Beck, U. \& Beck-Gernsheim, E. (2002) Individualization. London: Sage.

Berger, P. L., \& Luckmann, T. (1991). The social construction of reality: A treatise in the sociology of knowledge. UK: Penguin.

Bianchi, S.M., Milkie, M.A., Sayer, L.C., Robinson, J.P. (2000). Is anyone doing the housework? Trends in the gender division of household labor. Social Forces 79(1): 191-228. Blue, S., Shove, E., Carmona, C., \& Kelly, M. P. (2016). Theories of practice and public health: understanding (un) healthy practices. Critical Public Health, 26(1), 36-50.

Braun, V., Clarke, V., Hayfield, N., \& Terry, G. (2019). Thematic analysis. In P. Liamputtong, (Ed.), Handbook of Research Methods in Health Social Sciences (pp. 843-860). Singapore: Springer.

Burr, V. (2015). Social constructionism. London: Routledge.

Carlson, J. (2011) Subjects of stalled revolution: a theoretical consideration of contemporary American femininity. Feminist Theory, 12, 1, 75-91.

Canguilhem, G. (2002). [Writings on medicine] Écrits sur la médecine. Paris: Editions Seuil. Chamberlain, K. \& Lyons, A. (In press). Critical and qualitative approaches to behavior change. In M.S. Hagger, L. Cameron, K. Hamilton, N. Hankonen, \& T. Lintunen (Eds.), The Handbook of Behavior Change. Cambridge UK: Cambridge University Press.

Chowdhury, N., \& Gibson, K. (2019). This is (still) a man's world: Young professional women's identity struggles in gendered workplaces. Feminism \& Psychology, 0959353519850851.

Chowdhury, N., Gibson, K., \& Wetherell, M. (2019). Polyphonies of depression: The relationship between voices-of-the-self in young professional women aka 'top girls'. Health, 1363459319846934. 
Cornish, F. (2004). Making 'context' concrete: a dialogical approach to the society-health relation. Journal of health psychology, 9(2), 281-294.

Crawford, R. (1980). Healthism and the medicalization of everyday life. International Journal of Health Services, 10(3), 365-388.

Crawford, K., Lingel, J., \& Karppi, T. (2015). Our metrics, ourselves: A hundred years of self-tracking from the weight scale to the wrist wearable device. European Journal of Cultural Studies, 18(4-5), 479-496.

Cromby, J. (2007). Toward a psychology of feeling. International Journal of Critical Psychology, 21(94), 118.

Cromby, J. (2011). Affecting qualitative health psychology. Health Psychology Review, 5(1), 79-96.

del Río Carral, M. (2014). Focusing on "A Day in the Life": An Activity-Based Method for the Qualitative Analysis of Psychological Phenomena. Qualitative Research in Psychology, 11(3), 298-315.

del Río Carral, M. (2015). The Articulation of Different Life Domains among Female Senior Managers and Their Subjective Well-Being: Focusing on Meaning Constructions in Everyday Life. International Journal of Psychological Studies, 7(3), 157-175.

Demsky, C. A., Ellis, A. M., \& Fritz, C. (2014). Shrugging it off: Does psychological detachment from work mediate the relationship between workplace aggression and workfamily conflict? Journal of Occupational Health Psychology, 19(2), 195.

Elias, A. S., \& Gill, R. (2018). Beauty surveillance: The digital self-monitoring cultures of neoliberalism. European Journal of Cultural Studies, 21(1), 59-77.

Ehrenberg, A. (2008). [The tiredness of being] La fatigue d'être soi: dépression et société. Paris: Odile Jacob.

Engel, G. L. (1977). The need for a new medical model: A challenge for biomedicine. Science, 196, 129-136.

Engman, A. (2019). Embodiment and the foundation of biographical disruption. Social Science \& Medicine, 225, 120-127.

Foucault, M. (2009). [The utopic body and The heterotopias] Le corps utopique suivi de Les hétérotopies. Paris : Nouvelles éditions lignes.

Gherardi, S. (1994). The gender we think, the gender we do in our everyday organizational lives. Human relations, 47(6), 591-610. 
Gherardi, S., \& Murgia, A. (2014). What makes a "good manager"? Positioning gender and management in students' narratives. Equality, Diversity and Inclusion: An International Journal, 33(8), 690-707.

Gherardi, S. (1995). Gender, symbolism and organizational cultures. London: Sage.

Gergen, K. J. (2015). Culturally inclusive psychology from a constructionist

standpoint. Journal for the Theory of Social Behaviour, 45(1), 95-107.

Giddens, A. (1984). The Constitution of Society. Outline of the Theory of Structuration.

Cambridge: Polity.

Gill, R. (2017). The affective, cultural and psychic life of postfeminism: A postfeminist sensibility 10 years on. European Journal of Cultural Studies, 20(6), 606-626.

Gill, R., \& Donaghue, N. (2013). As if postfeminism had come true: The turn to agency in cultural studies of 'sexualisation'. In S. Madhok, A. Phillips, K. Wilson, \& C. Hemmings (Eds.), Gender, agency, and coercion (pp. 240-258). London: Palgrave Macmillan.

Gill, R., K. Kelan, E., \& M. Scharff, C. (2017). A postfeminist sensibility at work. Gender, Work \& Organization, 24(3), 226-244.

Gilleard, C., \& Higgs, P. (2015). Aging, embodiment, and the somatic turn. Age, Culture, Humanities: An Interdisciplinary Journal, 2(2015), 17-33.

Godin, G., \& Kok, G. (1996). The theory of planned behavior: A review of its applications to health-related behaviors. American Journal of Health Promotion, 11, 87-98.

Gough, B., \& Conner, M. T. (2006). Barriers to healthy eating amongst men: a qualitative analysis. Social science \& medicine, 62(2), 387-395.

Hargreaves, T. (2011). Practicing behaviour change: Applying social practice theory to proenvironmental behaviour change. Journal of Consumer Culture, 11(1), 79-99.

Laurier, E., McKie, L., \& Goodwin, N. (2000). Daily and lifecourse contexts of smoking. Sociology of Health and Illness, 22, 289-309.

Lee, C. (1998). Women's health: Psychological and social perspectives. London: Sage.

Lewis, J., Campbell, M., \& Huerta, C. (2008). Patterns of paid and unpaid work in Western Europe: gender, commodification, preferences and the implications for policy. Journal of European Social Policy, 18(1), 21-37. https://doi.org/10.1177/0958928707084450

Lewis, P., \& Simpson, R. (2017). Hakim revisited: Preference, choice and the postfeminist gender regime. Gender, Work \& Organization, 24(2), 115-133.

Lyonette, C., \& Crompton, R. (2015). Sharing the load? Partners' relative earnings and the division of domestic labour. Work, Employment and Society, 29(1), 23-

40. https://doi.org/10.1177/0950017014523661 
Lyons, A. C. (2009). Masculinities, femininities, behaviour and health. Social and personality psychology compass, 3(4), 394-412.

Lyons, A. C., \& Chamberlain, K. (2017). Critical health psychology. In Gough, B. (Ed.), The Palgrave handbook of critical social psychology (pp. 533-555). London: Palgrave Macmillan. Hakim, C. (2000). Work-lifestyle choices in the 21st century: Preference theory. Oxford: OUP.

Hargreaves, T. (2011). Practice-ing behaviour change: Applying social practice theory to proenvironmental behaviour change. Journal of consumer culture, 11(1), 79-99.

Hochschild, A. (1990) The Second Shift: Working Parents and the Revolution at Home. London: Piatkus.

Johnson, K. M., \& Fledderjohann, J. (2012). Revisiting “her” infertility: Medicalized embodiment, self-identification and distress. Social Science \& Medicine, 75(5), 883-891. Kan, M.Y., Sullivan, O., \& Gershuny, J. (2011). Gender convergence in domestic work: discerning the effects of interactional and institutional barriers from large-scale data. Sociology 45(2): 234-51.

Kelly, M. P., \& Barker, M. (2016). Why is changing health-related behaviour so difficult?. Public health, 136, 109-116.

Leder, D. (1992). A tale of two bodies: The Cartesian corpse and the lived body. In D. Leder (Ed.), The body in medical thought and practice (pp. 17-35). Dordrecht: Kluwer Academic. Macdonald, L. A. (2005). Wellness at work: protecting and promoting employee health and wellbeing. CIPD Publishing.

Martin, P. Y. (2003). "Said and done” versus "saying and doing” gendering practices, practicing gender at work. Gender \& society, 17(3), 342-366.

Martin, P. Y. (2006). Practising gender at work: Further thoughts on reflexivity. Gender, Work \& Organization, 13(3), 254-276.

Matarazzo, J. D. (1980). Behavioral health and behavioral medicine: Frontiers for a new health psychology. American Psychologist, 35, 807-817.

McRobbie, A. (2007). Top girls? Young women and the post-feminist sexual contract. Cultural studies, 21(4-5), 718-737.

Meier, P. S., Warde, A., \& Holmes, J. (2018). All drinking is not equal: how a social practice theory lens could enhance public health research on alcohol and other health behaviours. Addiction, 113(2), 206-213.

Merleau-Ponty, M. (1989). [Phenomenology of perception] Phénoménologie de la perception. Paris: Gallimard. 
Mielewczyk, F., \& Willig, C. (2007). Old clothes and an older look: The case for a radical makeover in health behaviour research. Theory \& Psychology, 17(6), 811-837.

Moisander, J., Gross, C., \& Eräranta, K. (2018). Mechanisms of biopower and neoliberal governmentality in precarious work: Mobilizing the dependent self-employed as independent business owners. Human Relations, 71(3), 375-398.

Murray, M. (2003). Narrative psychology and narrative analysis. In P. M. Camic, J. E.

Rhodes, \& L. Yardley (Eds.), Qualitative research in psychology: Expanding perspectives in methodology and design (pp. 95-112). Washington, DC: American Psychological Association.

Nelson, D. L., \& Burke, R. J. (2018). Gender, Work Stress, and Health. Washington, DC: American Psychological Association.

Nettleton, S. (2006). 'I just want permission to be ill': towards a sociology of medically unexplained symptoms. Social science \& medicine, 62(5), 1167-1178.

Ogden, J. (2003). Some problems with social cognition models: A pragmatic and conceptual analysis. Health Psychology, 22(4), 424.

Ogden, J. (2012). Health Psychology: A Textbook: A textbook. McGraw-Hill Education (UK). Poggio, B. (2006). Outline of a theory of gender practices. Gender, work \& organization, 13(3), 225-233.

Radley, A. (1995). The elusory body and social constructionist theory. Body \& Society, 1(2), $3-23$.

Radley, A. (2000). Health psychology, embodiment and the question of vulnerability. Journal of Health Psychology, 5(3), 297-304.

Reckwitz, A. (2002a). The status of the "material" in theories of culture: From "social structure" to "artefacts". Journal for the theory of social behaviour, 32(2), 195-217.

Reckwitz, A. (2002b). Toward a theory of social practices: A development in culturalist theorizing. European journal of social theory, 5(2), 243-263.

Riegel, K.F. (1976). The dialectics of human development. American Psychologist, 31, 689700 .

Riley, S., Evans, A., \& Robson, M. (2018). Postfeminism and health: Critical psychology and media perspectives. London: Routledge.

Saltonstall, R. (1993). Healthy bodies, social bodies: men's and women's concepts and practices of health in everyday life. Social science \& medicine, 36(1), 7-14. 
Santiago-Delefosse, M. (2014). The Need for an "Embodied-Societal-Psychological” Model of Illness Experience. In M. Murray (Ed.), Critical health psychology (36-54). UK:

Macmillan International Higher Education.

Sheets-Johnstone, M. (2015). The corporeal turn: An interdisciplinary reader. UK: Andrews UK Limited.

Sniehotta, F., Presseau, J., \& Araujo-Soares, V. (2014). Time to retire the theory of planned behaviour. Health Psychology Review, 8, 1-7. doi: 10.1080/17437199.2013.869710 Sonnentag, S., \& Fritz, C. (2015). Recovery from job stress: The stressor-detachment model as an integrative framework. Journal of Organizational Behavior, 36(1), 72-103.

Thévenot, L. (2001). Pragmatic regimes governing the engagement with the world. In T.R. Vallas, S. (2015). Accounting for precarity: Recent studies of labor market uncertainty. Contemporary Sociology: A Journal of Reviews 44(4): 463-469.

Tomkins L. \& Pritchard, K. (2019). Health at work: Critical perspectives. London: Routledge Vygotski, L.S. (1997). [Thought and language] Pensée et langage. Paris: La Dispute.

Weaver, L. (2017). Rushing Woman's Syndrome: The Impact of a Never-ending To-do List and how to Stay Healthy in Today's Busy World. UK: Hay House, Inc.

West, C., \& Zimmerman, D. H. (1987). Doing gender. Gender \& society, 1(2), 125-151. Winch, A. (2015). Feminism, generation and intersectionality. Soundings, 58(58), 8-20. Whitaker, C., Gough, B., Fawkner, H., \& Deighton-Smith, N. (2019). Young men's body dissatisfaction: A qualitative analysis of anonymous online accounts. Journal of health psychology, 1359105319832352. 